\title{
Influence of Tantalum Addition on Microstructure and Mechanical Properties of the NiAl-Based Eutectic Alloy
}

\author{
L. Y. Sheng, ${ }^{a, 1}$ B. N. Du, ${ }^{a}$ C. Lai, ${ }^{a}$ J. T. Guo, ${ }^{b}$ and T. F. Xi ${ }^{a}$ \\ ${ }^{a}$ Shenzhen Institute, Peking University, Shenzhen, China \\ ${ }^{\mathrm{b}}$ Institute of Metal Research, Chinese Academy of Sciences, Shenyang, China \\ ${ }^{1}$ lysheng@yeah.net
}

NiAl-28Cr-6Mo or NiAl-Cr(Mo) eutectic alloys with different degree of tantalum (Ta) addition have been fabricated and investigated. The microstructural characterization shows that minor Ta addition results in the formation of $\mathrm{Cr}_{2} \mathrm{Ta}$ Laves phase with C14 crystal structure. Small Laves phases are prone to precipitation along $\mathrm{Cr}(\mathrm{Mo})$ phase boundary, while large/bulk ones are formed in the intercellular region. As compared with the $\mathrm{NiAl-Cr}(\mathrm{Mo})$ eutectic alloy, minor Ta addition can refine $\mathrm{Cr}(\mathrm{Mo})$ and NiAl eutectic lamella in the core of eutectic cell but coarsen the Cr(Mo) and NiAl phase in the fringe of eutectic cell. An increased Ta addition invokes coarsening of $\mathrm{Cr}(\mathrm{Mo})$ and NiAl phases in the intercellular region and enhances Laves phase precipitation in the intercellular region. When the Ta addition increases to 2.0 at.\%, the modified alloy mainly comprises ultrafine eutectic cell core and coarse $\mathrm{Cr}(\mathrm{Mo})$ and NiAl phases, which are semi-separated by NiAl dendritic and bulk Laves phase. The results confirm that the appropriate Ta addition can significantly improve the high-temperature strength with a feeble effect on room-temperature ductility, which can be ascribed to the microstructure optimization induced by the Ta addition. However, further Ta addition strongly affects the cellular eutectic microstructure and is detrimental for the room-temperature ductility. The appropriate Ta content in the $\mathrm{NiAl-Cr}(\mathrm{Mo})$ eutectic alloy should be about 1.0 at.\%.

Keywords: NiAl-based eutectic alloy, tantalum, Laves phase, microstructure, mechanical properties.

Introduction. Intermetallic compounds, due to their excellent properties, have been paid much attention recently [1-4]. As one type of high-temperature intermetallic compound, nickel aluminum (NiAl) possesses many advantages, such as excellent oxidation resistance, high melting point (about $1911 \mathrm{~K}$ ), excellent thermal conductivity and low density [3-6]. It used to be considered as the most promising candidate of the superalloy to work in aircraft engine [7]. However, later it was found that NiAl binary alloy exhibits high brittleness at room temperature and insufficient creep strength at elevated temperatures, which hinders its industrial application $[7,8]$. To resolve this problem and improve its mechanical properties, numerous technologies were applied and plenty of NiAl-based materials were developed $[4,9,10]$. Among them, the formation of pseudo-binary or ternary eutectic system by introducing in-situ refractory phase has been considered as a convenient method, and the $\mathrm{NiAl}-\mathrm{Cr}(\mathrm{Mo})$ eutectic alloy is treated as the most promising one due to the balance of its fracture toughness and creep strength [11].

Though the room-temperature fracture toughness of $\mathrm{NiAl}-\mathrm{Cr}(\mathrm{Mo})$ eutectic alloy is improved, its strength at elevated temperature is still lower than that of the nickel based superalloy $[12,13]$. Previous investigations $[14,15]$ revealed that the introducing of stiffness phase can strongly enhance the strength of the NiAl-based alloy at elevated temperatures, such as Laves phase, Heusler phase and so on. Bhowmik et al. [16] reported that the appropriate addition of Ta leads to the precipitation of Laves phase, while Johnson et al. [17] found that the addition of Ta to NiAl would promote the forming of NiAlTa and $\mathrm{Ni}_{2}$ AlTa phases. Zeumer and Sauthoff [18] revealed that the Ta addition can improve the strength of $\mathrm{NiAl}$ at elevated temperatures by two times. Thus, the introduction of stiffness phases would improve the high-temperature strength of NiAl-based alloy, while these 
stiffness phases were apt to precipitate along the phase or eutectic cell boundaries, which would deteriorate the room-temperature fracture toughness [19]. Therefore, the appropriate addition of refractory metal is critical for fabrication of NiAl-based alloys. In the present study, various Ta-doped $\mathrm{NiAl}-\mathrm{Cr}(\mathrm{Mo})$ eutectic alloys are prepared and the detailed investigations on their microstructure and mechanical behavior are carried out to evaluate the most suitable addition.

1. Experimental. As investigated in the previous researches, the addition of Ta would consume the $\mathrm{Cr}$ mainly to form the Laves phase. To keep the alloy in the eutectic composition, the $\mathrm{Ni}$ and $\mathrm{Al}$ contents are decreased equivalently. The alloys used in the present research are $\mathrm{Ni}-(33-x / 2) \mathrm{Al}-28 \mathrm{Cr}-6 \mathrm{Mo}-x \mathrm{Ta}$ (at.\%) of nominal composition with $x=0,0.5,1.0$, and 2.0, which were fabricated by vacuum non-consumed electric arc-melting furnace from pure metal. Every alloy button ingot was overturned and remelted for three times to homogenize the alloy composition. Since the weight loss was so low, the designed nominal alloy composition was regarded as the actual one. The prepared alloys were heat-treated at $1473 \mathrm{~K}$ for $20 \mathrm{~h}$ in evacuated silica capsules and then cooled to room temperature in air.

Microstructure observations were performed via a FEI Quanta 600 scanning electron microscopy (SEM) with energy disperse spectroscopy (EDS). The analyses of constituent phases were performed by X-ray diffraction (XRD) carried out on a D8 Discover X-ray diffractometer using $\mathrm{CuK} \alpha$ - radiation. The specimens for SEM and XRD were prepared by the conventional metallographic method. The characterization of the precipitate phase was performed via a JEM-2100 transmission electron microscopy (TEM). Thin foils for TEM observation were cut out from the alloy button ingots by electro-discharge machining (EDM); then they were polished to $40 \mu \mathrm{m}$ and shaped into $3 \mathrm{~mm}$ in diameter followed by the ion milling. The compression specimens with size of $\varnothing 5 \times 8 \mathrm{~mm}$ were cut from the alloy button ingots by EDM and all surfaces were polished. The Gleeble 1500 test machine was employed to perform compression test in air at room temperature, 1273 and $1373 \mathrm{~K}$ with an initial strain rate of $2 \cdot 10^{-3} \mathrm{~s}^{-1}$.

\section{Results and Discussion.}

2.1. Microstructure Evolution. SEM observations on the Ni-(33-x/2)A1-28Cr-6Mo- $x \mathrm{Ta}$ eutectic alloys are shown in Fig. 1. Clearly, the alloys mainly possess gray $\mathrm{Cr}(\mathrm{Mo})$ and black NiAl phases, which compose the eutectic structure and exhibit the chrysanthemumlike shape. Without the Ta addition, the NiAl-Cr(Mo) eutectic alloy shows a typical cellular eutectic structure depicted in Fig. 1a. The $\mathrm{Cr}(\mathrm{Mo})$ and NiAl phases in the core exhibit fine rod-like shapes and are regularly arranged. In the fringe region of the eutectic cell, $\mathrm{Cr}(\mathrm{Mo})$ and NiAl phases exhibit radially emanating pattern extending to the eutectic cell boundary. The $\mathrm{Cr}(\mathrm{Mo})$ and $\mathrm{NiAl}$ phases in the fringe region are much coarser that those in the core. Moreover, the volume percentage of coarse $\mathrm{Cr}(\mathrm{Mo})$ and $\mathrm{NiAl}$ eutectic lamella in the alloy without Ta addition is lower by about $40 \%$. With the minor addition of Ta, the eutectic cell becomes smaller, but the amount of coarse $\mathrm{Cr}(\mathrm{Mo})$ and $\mathrm{NiAl}$ phases increases, as is shown in Fig. 1b. The volume percentage of the $\mathrm{Cr}(\mathrm{Mo})$ and NiAl eutectic lamella in the alloy is more than $60 \%$. In addition, a minor Ta addition promotes the precipitation of white phases, most of which are randomly distributed along the eutectic cell boundary with the relative bulk size. The EDS test indicates the white phase mainly includes $\mathrm{Cr}, \mathrm{Ta}, \mathrm{Ni}$, and $\mathrm{Al}$. Based on the previous researches $[16,17]$, the white phase should be the Laves phase. Additionally, the primary NiAl phases of moderate sizes are formed along the eutectic cell boundary. With the Ta addition increase to 1 at. \%, a intercellular region is formed between the eutectic cells, and more primary $\mathrm{NiAl}$ phases are formed in the region of a near-spherical shape, as exhibited in Fig. 1c. The Laves phases mainly precipitate along the phase boundary and are scattered in the intercellular region. Furthermore, this phase also precipitates in the primary NiAl phase. In this alloy, fine $\mathrm{Cr}(\mathrm{Mo})$ and NiAl eutectic lamella and primary NiAl phase have nearly the same volumetric percentage, which is 
smaller than that of the coarse $\mathrm{Cr}(\mathrm{Mo})$ and NiAl eutectic lamella. When the Ta addition reaches 2 at. \%, the microstructure of the alloy exhibits a strong variation, as is shown in Fig. 1d. Further increase in the width of intercellular region containg numerous primary NiAl dendrite, bulk Laves phase, as well as coarse $\mathrm{Cr}(\mathrm{Mo})$ and NiAl phases, is observed. The Laves phases are distributed along the eutectic cell boundary semi-continuously and the primary $\mathrm{NiAl}$ has coarse rod-like or flower-like shapes. The volumetric percentage of the fine $\mathrm{Cr}(\mathrm{Mo})$ and $\mathrm{NiAl}$ eutectic lamella is smaller than that of primary NiAl and coarse $\mathrm{Cr}(\mathrm{Mo})$ and $\mathrm{NiAl}$ phases.
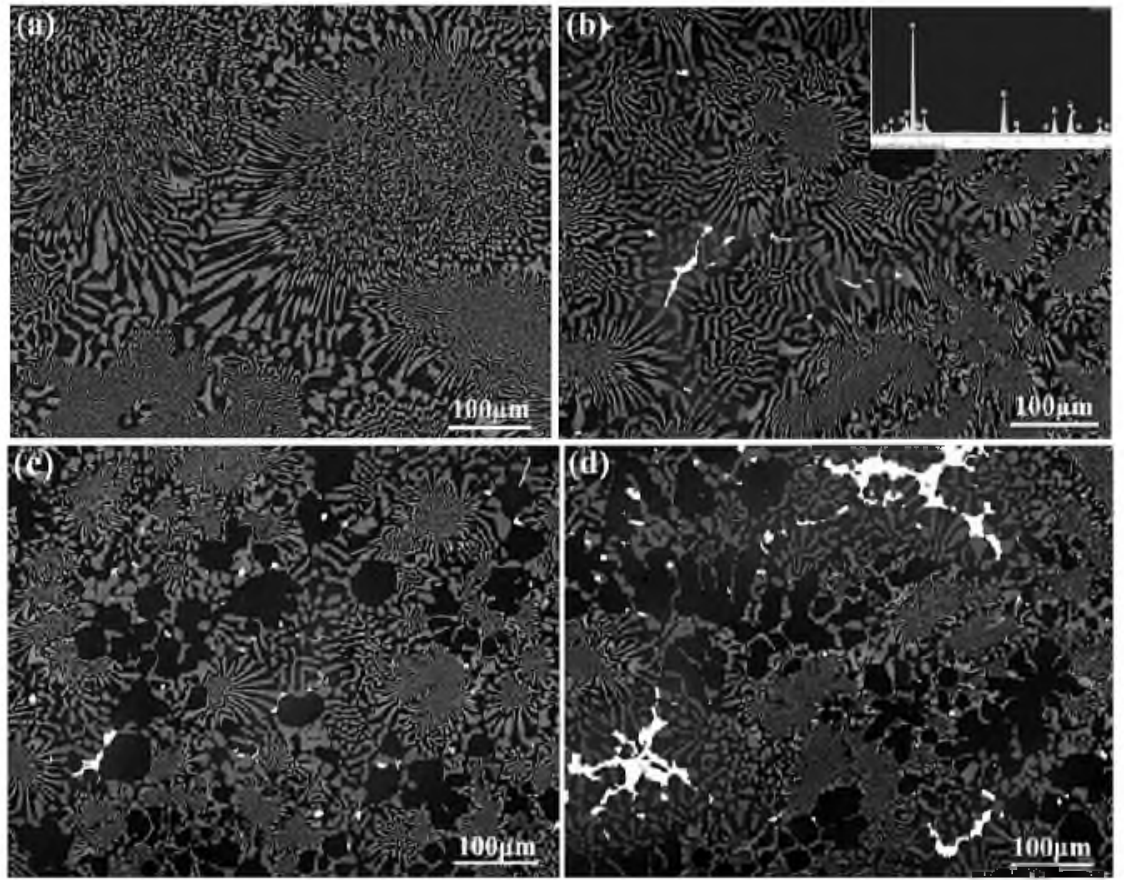

Fig. 1. Microstructure of the Ni-(33-x/2)Al-28Cr-6Mo-xTa eutectic alloy: (a) $x=0$; (b) $x=0.5$ (inset image showing the EDS analysis of the white phase); (c) $x=1.0$; (d) $x=2.0$.

To analyze the phase and crystal evolution of the NiAl-Cr(Mo) eutectic alloy for various Ta additions, the XRD analyses were carried out, as shown in Fig. 2. Obviously, with the addition of Ta, the crystal orientation preference and precipitate change greatly. As shown in the XRD pattern of $\mathrm{NiAl}-\mathrm{Cr}(\mathrm{Mo})$ eutectic alloy, the (110) crystal plane corresponds to the strongest diffraction peaks of $\mathrm{Cr}(\mathrm{Mo})$ and $\mathrm{NiAl}$ phases, while other diffraction peaks are feeble. However, a minor Ta addition promotes more $\mathrm{Cr}(\mathrm{Mo})$ and NiAl phases to grow along the (211) crystal plane. When the Ta content reaches 1 at. \%, the $\mathrm{XRD}$ pattern indicates the precipitation of Laves phases. In the alloy with 2 at. $\% \mathrm{Ta}$ addition, the amounts of $\mathrm{NiAl}$ along the (100) crystal plane, $\mathrm{NiAl}$ and of $\mathrm{Cr}(\mathrm{Mo})$ along the (200) crystal plane increase obviously. Moreover, strong diffraction peaks of Laves phase can be observed, which finding is in agreement with the SEM observations. Based on the XRD pattern, the formed Laves phase should have the C14 crystal structure.

SEM observation on the 1 at.\% Ta-doped NiAl-Cr(Mo) eutectic alloy shows plenty of coarse precipitates in $\mathrm{Cr}(\mathrm{Mo})$ and $\mathrm{NiAl}$ phases, as shown in Fig. 3a. In the bulk NiAl phase, the $\alpha$-Cr precipitates exhibit two kinds of morphologies: one is spherical, while the other has a dendritic shape. In contrast to $\alpha$ - $\mathrm{Cr}$ precipitates, $\beta$-NiAl ones mainly exhibit a near-spherical shape in $\mathrm{Cr}(\mathrm{Mo})$ phase. The TEM observation $\mathrm{fn}$ the precipitates reveals abundant interface dislocations forming along the $\beta$-NiAl precipitate interface, as shown in 
Fig. 3b. Additionally, it was also found that the interface dislocations extend into the $\beta$-NiAl precipitate, and some precipitates are fully covered. Based on the former investigation [20], $\mathrm{Cr}(\mathrm{Mo})$ and $\mathrm{NiAl}$ phases are known to have good interface matching, due to the similar crystal structure and lattice constant, especially along the (100) crystal plane. However, a small difference between the lattice constants of $\mathrm{Cr}(\mathrm{Mo})$ and $\mathrm{NiAl}$ phases also causes the lattice distortion and results in the interface dislocations. Li et al. [21] reported that the presence of refractory metal would amplify the difference of lattice constant between $\mathrm{Cr}(\mathrm{Mo})$ and $\mathrm{NiAl}$ phases, which could bring more interface dislocations. In the present research, most Ta would be incorporated into the Laves phase and the residual would solid solute in $\mathrm{Cr}(\mathrm{Mo})$ phase, as is indicated in Table 1. Moreover, with increased Ta content, the content of Mo decreases but that of $\mathrm{Al}$ increases in $\mathrm{Cr}(\mathrm{Mo})$ phase. Based on the microstructure characterization, it can be concluded that the increased $\mathrm{Ta}$ content promotes the precipitation. In combination with the composition, the increased Ta content would be concentrated in the precipitates and phase boundary. Due to the difference in the atomic radii, the changes of composition would result in greater lattice distortion along the phase boundary and numerous interface dislocations.

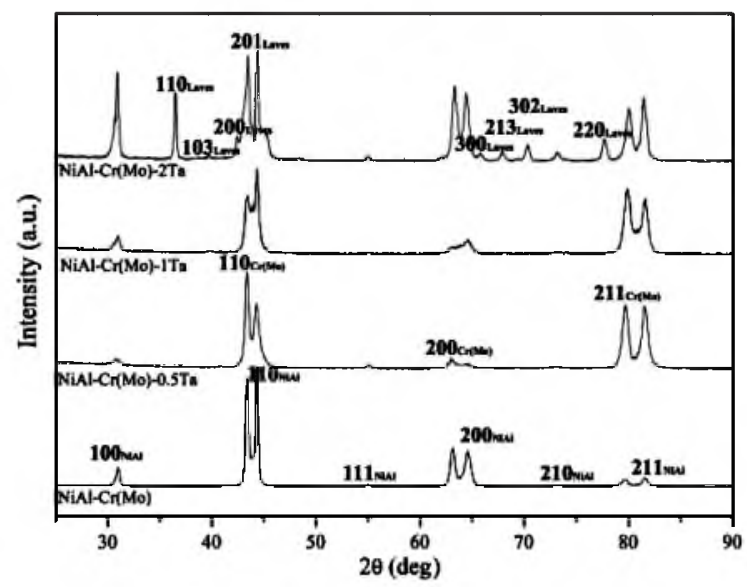

Fig. 2. XRD patterns of NiAl-Cr(Mo) eutectic alloy with different Ta contents.
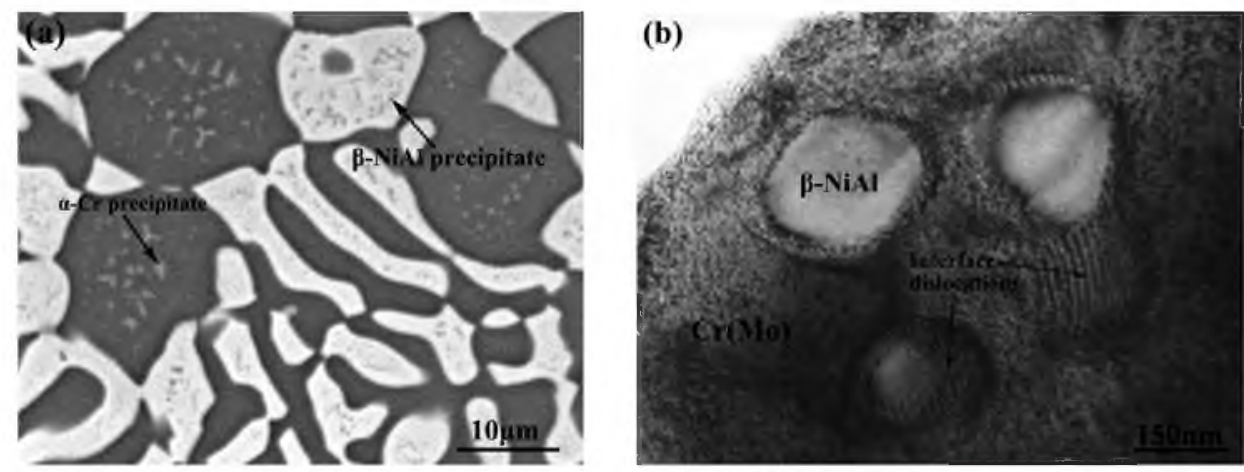

Fig. 3. Morphology of the $\beta$-NiAl and $\alpha$-Cr precipitates in the eutectic alloy: (a) SEM image of precipitate in the intercellular region; (b) TEM image of $\beta$-NiAl precipitate and interface dislocations.

Observations on the Laves phases were carried out by SEM and TEM, the results being shown in Fig. 4. Clearly, small Laves phases are prone to precipitate in the tip of $\mathrm{Cr}(\mathrm{Mo})$ phase in the intercellular region, as is shown in Fig. 4a. The precipitated Laves phase has irregular polyhedron shape and mainly contains $\mathrm{Cr}$ and Ta. The TEM observation 
$\mathrm{T}$ a $\mathrm{b} 1$ e 1

Composition of Constitute Phases in the NiAl-Cr(Mo) Eutectic Alloys Doped with Different Amount of Ta (at.\%)

\begin{tabular}{|c|c|c|c|c|c|c|}
\hline Alloy & Phase & $\mathrm{Al}$ & $\mathrm{Ni}$ & $\mathrm{Cr}$ & Mo & Ta \\
\hline \multirow{2}{*}{$0.5 \mathrm{Ta}$} & $\mathrm{Cr}(\mathrm{Mo})$ & 5.66 & 3.52 & 73.47 & 15.90 & 1.45 \\
& $\mathrm{NiAl}$ & 48.34 & 49.00 & 2.66 & - & - \\
& Laves phase & 13.25 & 15.77 & 31.05 & 6.91 & 33.02 \\
\hline \multirow{2}{*}{$1 \mathrm{Ta}$} & Cr(Mo) & 6.93 & 11.11 & 68.09 & 12.44 & 1.44 \\
& NiAl & 49.35 & 47.37 & 3.10 & - & - \\
& Laves phase & 12.37 & 16.10 & 34.47 & 7.97 & 29.09 \\
\hline \multirow{2}{*}{$2 \mathrm{Ta}$} & Cr(Mo) & 7.75 & 11.89 & 68.39 & 10.69 & 1.27 \\
& NiAl & 47.84 & 48.72 & 3.44 & - & - \\
& Laves phase & 12.27 & 16.27 & 35.22 & 6.48 & 29.76 \\
\hline
\end{tabular}

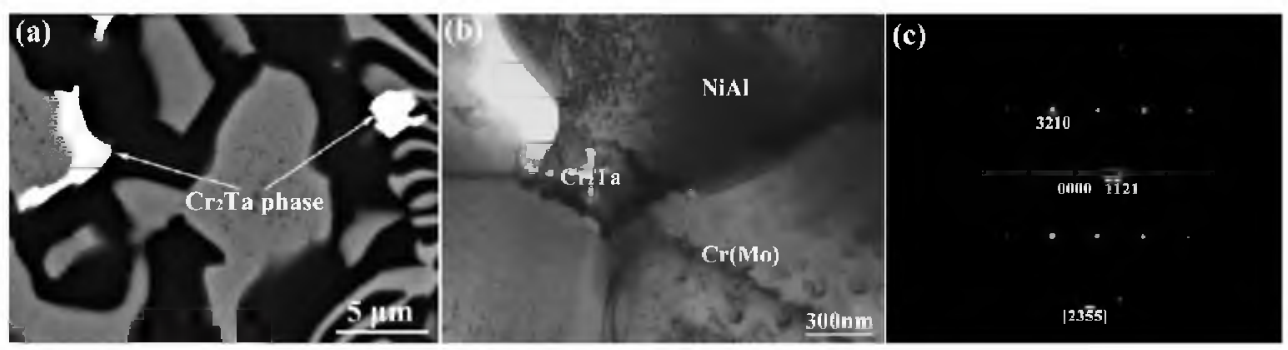

Fig. 4. Morphology of $\mathrm{Cr}_{2} \mathrm{Ta}$ phase: (a) SEM image of $\mathrm{Cr}_{2} \mathrm{Ta}$ phase along phase boundary; (b) TEM image $\mathrm{Cr}_{2} \mathrm{Ta}$ precipitate; (c) SAED pattern of $\mathrm{Cr}_{2} \mathrm{Ta}$ precipitate along [2355].

on the Laves phase along the phase boundary revealed that small precipitates aggregate together, as shown in Fig. 4b. The selected area electron diffraction (SAED) pattern along the [23 $\overline{5}$ ] zone axis confirms the Laves phase is $\mathrm{Cr}_{2} \mathrm{Ta}$ phase having a hexagonal crystal lattice and the space group of P63/mmc with $a=b=0.4925 \mathrm{~nm}, c=0.8062 \mathrm{~nm}$, as shown in Fig. 4c. The SAED pattern also proves the Laves phase have a C14 structure. According to the phase diagrams of the $\mathrm{Cr}$-Ta system and former investigations $[16,22]$, the $\mathrm{Cr}_{2} \mathrm{Ta}$ phase at room temperature should have a cubic $\mathrm{C} 15$ structure rather than hexagonal $\mathrm{C} 14$ one. In the present research, the main difference is the presence of the $\mathrm{Ni}, \mathrm{Al}$, and $\mathrm{Mo}$ in the alloy. The EDS analysis of the Laves phase also confirmed the presence of $\mathrm{Ni}, \mathrm{Al}$, and $\mathrm{Mo}$. Considering the atomic radii, it can be deduced that, in the new Laves phase, $\mathrm{Ni}$ and $\mathrm{Al}$ atoms primarily substitute those of $\mathrm{Cr}$, while Ta atoms are maily substituted by Mo ones. Since Laves phases precipitate at the end of the solidification process, the constitutional supercooling enhances the solidification rate and suppresses the diffusion. The solid solution elements may prevent the crystal transformation and thus preserve the C14 crystal structure in the Laves phase at room temperature. Moreover, the electron-to-atom ratio (e/a) also controls the crystal structure of Laves phase [23]. In the present study, the solid soluted $\mathrm{Ni}, \mathrm{Al}$, and Mo in the Laves phase would affect the electron-to-atom ratio (e/a) and promote its deviation from the original one, which preserves the C14 crystal structure of the $\mathrm{Cr}_{2} \mathrm{Ta}$ Laves phase at room temperature.

According to the previous findings [16, 17], under the equilibrium solidification conditions, the solid solubility of $\mathrm{Ta}$ in $\mathrm{Cr}(\mathrm{Mo})$ and NiAl phases is almost zero. Though a small amount of $\mathrm{Ta}$ is detected in $\mathrm{Cr}(\mathrm{Mo})$ phase in the present stuidy, it may be located in small precipitates. Due to the high melting point, the added Ta would act as the nuclei for the solidification starty. So it can be found that the eutectic cell becomes fine with the 
addition of Ta. With the solidification proceeding, some amount of Ta would be expelled to the front of liquid/solid interface. Because of the tip radius of eutectic alloy solidification, the concentration of $\mathrm{Ta}$ at phase interface would be higher and enhance the undercooling of this region, which promotes the equilibrium growth of $\mathrm{Cr}(\mathrm{Mo}) / \mathrm{NiAl}$ lamella and handicaps their merging. Thus, the Ta-doped NiAl-Cr(Mo) eutectic alloy exhibits ultrafine lamella eutectic structure in the core of eutectic cell. When the solidification continues, more Ta is concentrated along the liquid/solid interface, which would result in large-scale constitutional supercooling. Then the $\mathrm{Cr}(\mathrm{Mo})$ and NiAl phases begin to merge and coarsen, so that the coarse $\mathrm{Cr}(\mathrm{Mo}) / \mathrm{NiAl}$ eutectic lamella is observed in the fringe of the eutectic cell. At the end of the solidification, the constitutional supercooling caused by high concentration of Ta promotes the nuclei in liquid and its rapid growth, which results in the formation of bulk $\mathrm{Cr}(\mathrm{Mo})$ and NiAl phases. Moreover, the formation of Laves phase consumes more $\mathrm{Cr}$ content and deviates the composition of the residual alloy liquid from the eutectic point, which results in the appearance of bulk NiAl phase in the alloy with 1.0 and 2.0 at. \% Ta addition.

2.2. Mechanical Properties. The compression properties of various Ta-doped $\mathrm{NiAl}-\mathrm{Cr}(\mathrm{Mo})$ eutectic alloys at room and high temperatures are given in Fig. 5. With the Ta addition increasing, the room-temperature yield strength of the alloy is improved gradually, but the compressive ductility is somewat reduced, as is shown in Fig. 5a. The alloy with 2.0 at. $\%$ Ta exhibits the minimum compressive ductility, which lower by about $10 \%$ than that of the alloy with no Ta addition. Noteworthy is that the NiAl-Cr(Mo) eutectic alloy with 1.0 Ta addition has nearly the same compressive ductility as the alloy with no Ta addition. The elevated-temperature strength of the Ta-doped $\mathrm{NiAl}-\mathrm{Cr}(\mathrm{Mo})$ eutectic alloy has a similar tendency, as indicated in Fig. 5b. With the increased Ta content, the yield strength of alloys at 1273 and $1372 \mathrm{~K}$ increases firstly and then falls down, reaching the maximum at 1.0 at.\% Ta addition. As compared with the yield strength at $1273 \mathrm{~K}$, the variation of the yield strength at $1373 \mathrm{~K}$ is higher, especially for the alloy with 0.5 and 2.0 at. $\%$ Ta addition. For example, the yield strength at $1373 \mathrm{~K}$ of the alloy with 0.5 at.\% Ta addition is higher by about $30 \%$ than that of the alloy with no Ta addition. On the contrary, the yield strength at $1273 \mathrm{~K}$ of the alloy with 0.5 at. \% Ta addition is about $15 \%$ higher than that of the alloy without Ta addition. Moreover, the yield strength reduction of the alloy with 2.0 at.\% addition of Ta at $1373 \mathrm{~K}$ is more significant than that at $1273 \mathrm{~K}$. These findings indicate that Ta addition can effectively enhance the elevated-temperature strength of the NiAl-Cr(Mo) eutectic alloy.

Based on the former investigations [24-26], the mechanical properties of the eutectic alloy are closely related to its microstructure, especially the eutectic cell size and eutectic lamella. Fine eutectic cells and lamella are beneficial for the room-temperature strength and ductility but dertimental for the elevated-temperature strength. Moreover, if the eutectic lamella is too coarse, the room-temperature mechanical properties will be deteriorated. Hence it is easy to grasp that Ta addition improves the strength of the alloy at room temperature, because it refines the eutectic cell and lamella. However, fine eutectic lamella in the core of eutectic cell can take advantage of the bridging or delamination effects and improve the compressive ductility. However, the Ta addition results in the coarsening of $\mathrm{Cr}(\mathrm{Mo})$ and $\mathrm{NiAl}$ along intercellular region and the precipitation of bulk Laves phase, which would be detrimental for the compressive ductility. As shown in Fig. 6a, the crack propagates preferably along the boundary of eutectic cell and coarse phase. Therefore, the compressive ductility of Ta-doped NiAl-Cr(Mo) eutectic alloy is not higher than that of alloy without $\mathrm{Ta}$ addition. Additionally, some dislocations are observed in the NiAl phase after the compression at room temperature, as shown in Fig. 6b. It means the NiAl phase is subjected to deformation, which can improve its compressive ductility. Moreover, the spherical NiAl phase is beneficial for the compressive deformation [27], so the 1.0 at.\% Ta-doped NiAl-Cr(Mo) eutectic alloy possesses relatively higher compressive ductility and strength. 


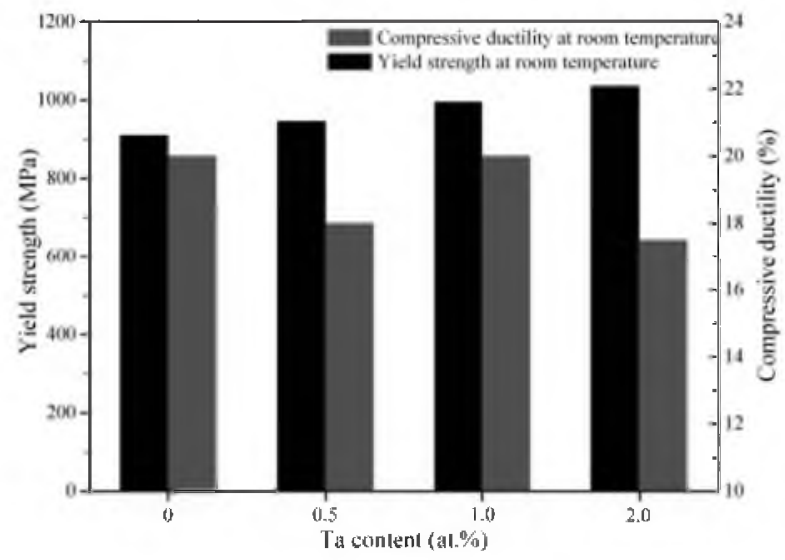

a

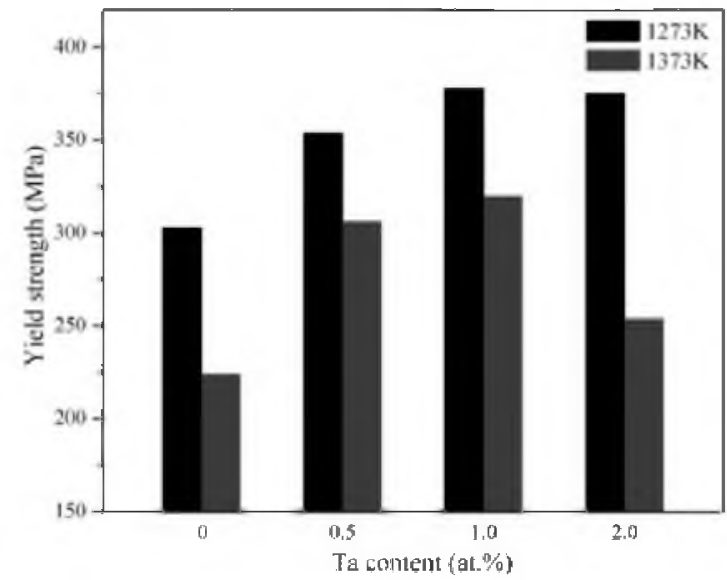

b

Fig. 5. Mechanical properties of NiAl-Cr(Mo) eutectic alloy with different Ta contents: (a) yield strength and compressive ductility at room temperature; (b) yield strength at 1273 and $1373 \mathrm{~K}$.
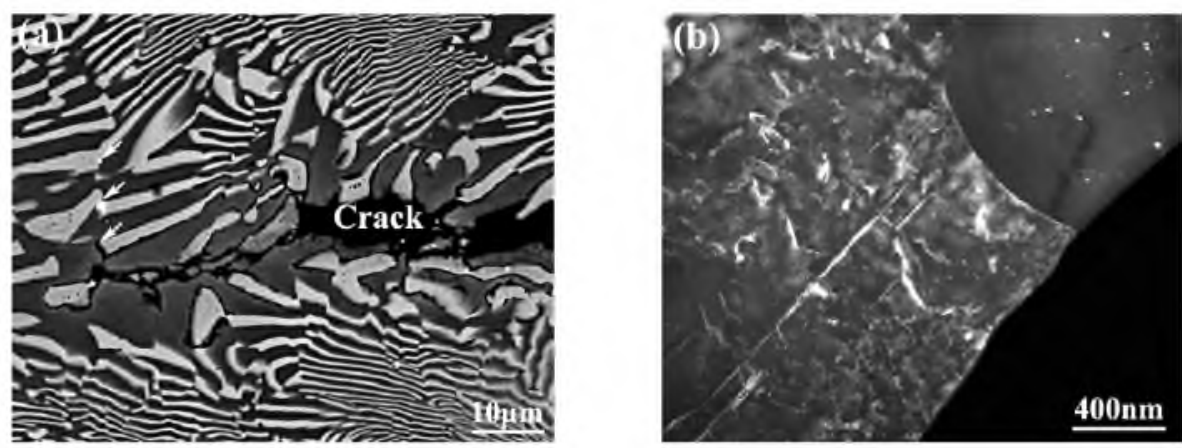

Fig. 6. Morphology of cracks and dislocations in the compressive specimen at room temperature: (a) propagation of crack along eutectic cell boundary; (b) dislocations in NiAl phase.

At high temperature, the morphology and size of the $\mathrm{Cr}(\mathrm{Mo})$ and $\mathrm{NiAl}$ phases become more critical for the alloy strength. Fine $\mathrm{NiAl} / \mathrm{Cr}(\mathrm{Mo})$ lamella and bulk NiAl phase are both detrimental, because they are easily deformed. Moreover, the enrichment Ta along the bulk 
phase boundary is higher than that along the fine one, which would increase the distortion and width of the interface dislocations. Considering the obstruction of interface dislocations on the deformation dislocation motion, more interface dislocations would invoke a higher deformation resistance. Thus, Ta-doped NiAl-Cr(Mo) eutectic alloys with relatively coarse $\mathrm{Cr}(\mathrm{Mo})$ and $\mathrm{NiAl}$ phases possess the improved high-temperature strength. Moreover, the precipitation of Laves phase also contributes to the strength improvement. However, it also can be found that the yield strength at $1373 \mathrm{~K}$ is lower than that at $1273 \mathrm{~K}$, especially the alloys with 2.0 an zero Ta at.\% addition. According the recent findings [28, 29], the yield strength of NiAl drops sharply with the temperature, and then the bulk NiAl dendritic tends to deform rapidly at higher temperatures, which would accelerate the yielding and strength reduction. Therefore, the yield strength of the eutectic alloy with $2.0 \mathrm{Ta}$ at. $\%$ addition at $1373 \mathrm{~K}$ is strongly reduced, as compared with that at $1273 \mathrm{~K}$. Nevertheless, the yield strength of alloy with $1.0 \mathrm{Ta}$ at. $\%$ addition at $1373 \mathrm{~K}$ is still higher than that of the alloy without Ta addition at $1273 \mathrm{~K}$, which indicates that the appropriate Ta addition can improve the elevated-temperature strength of the NiAl-based eutectic alloys.

\section{Conclusions}

1. A minor Ta addition promotes the precipitation of $\mathrm{Cr}_{2} \mathrm{Ta}$ Laves phase possessing the C14 crystal structure. The small Laves phase precipitates preferably along the phase boundary, while the bulk Laves phase is apt to form in the intercelluar region.

2. As compared with the NiAl-Cr(Mo) eutectic alloy, a minor Ta addition can refine the eutectic lamella in the core of eutectic cell but coarsen the $\mathrm{Cr}(\mathrm{Mo})$ and NiAl phase in the fringe of eutectic cell. With an increase in Ta content, $\mathrm{Cr}(\mathrm{Mo})$ and NiAl phases coarsen significantly in the intercellular region and more Laves phase precipitate. When the Ta content reaches 2.0 at. \%, the modified alloy mainly comprises ultrafine eutectic cell core and coarse $\mathrm{Cr}(\mathrm{Mo})$ and NiAl phases, which are semi-separated by NiAl dendritic and bulk Laves phases.

3. An appropriate Ta addition can significantly improve the high-temperature strength obviously with a feeble effect on the room-temperature ductility, which can be attributed to the microstructure optimization induced by the Ta addition. The superficial Ta addition can destroy the cellular eutectic microstructure, which is detrimental for the room-temperature ductility. The appropriate $\mathrm{Ta}$ addition in the $\mathrm{NiAl}-\mathrm{Cr}(\mathrm{Mo})$ eutectic alloy should be about 1.0 at. $\%$.

Acknowledgments. The authors are grateful to the Shenzhen International Cooperative Research Project(GJHZ20140419114548516), the Shenzhen Technology Innovation Plan (CXZZ20140731091722497 and CXZZ20140419114548507), China Postdoctoral Science Foundation (2015M580923) and Shenzhen Basic Research Project (JCYJ20140419114548515, JCYJ20150625155931806, and JCYJ20160407090231002) for financial support.

1. L. Y. Sheng, F. Yang, J. T. Guo, et al., "Investigation on NiAl-TiC- $\mathrm{Al}_{2} \mathrm{O}_{3}$ composite prepared by self-propagation high temperature synthesis with hot extrusion," Compos. Part B-Eng., 45, No. 1, 785-791 (2013).

2. Y. Feng, G. E. McGuire, O. A. Shenderova, et al., "Fabrication of copper/carbon nanotube composite thin films by periodic pulse reverse electroplating using nanodiamond as a dispersing agent," Thin Solid Films, 615, 116-121 (2016).

3. R. D. Noebe, R. R. Bowman, and M. V. Nathal, "Physical and mechanical properties of the B2 compound NiAl," Int. Mater. Rev., 38, 193-232 (1993).

4. L. Y. Sheng, F. Yang, T. F. Xi, et al., "Microstructure evolution and mechanical properties of $\mathrm{Ni}_{3} \mathrm{Al} / \mathrm{Al}_{2} \mathrm{O}_{3}$ composite during self-propagation high-temperature synthesis and hot extrusion," Mater. Sci. Eng. A, 555, 131-138 (2012). 
5. L. Y. Sheng, "Microstructure and wear properties of the quasi-rapidly solidified $\mathrm{NiAl} / \mathrm{Cr}(\mathrm{Mo}, \mathrm{Dy})$ hypoeutectic alloy," Strength Mater., 48, No. 1, 107-112 (2016).

6. J. M. Yang, S. M. Jeng, K. Bain, and R. A. Amato, "Microstructure and mechanical behavior of in-situ directional solidified $\mathrm{NiAl} / \mathrm{Cr}(\mathrm{Mo})$ eutectic composite," Acta Mater., 45, No. 1, 295-305 (1997).

7. L. Y. Sheng, "Microstructure characteristics and mechanical properties of $\mathrm{NiAl} / \mathrm{Cr}$ (Hf, Ho) in situ composite," Mater. Res. Innov., 19, S9-111-S9-115 (2015).

8. R. Darolia, "NiAl alloys for high-temperature structural applications," JOM, 43, No. 3 , 44-49 (1991).

9. L. Y. Sheng, W. Zhang, C. Lai, et al., "Microstructure and mechanical properties of Laves phase strengthening $\mathrm{NiAl}$ base composite fabricated by rapid solidification," Acta Metall. Sin., 49, No. 11, 1318-1324 (2014).

10. L. Y. Sheng, F. Yang, T. F. Xi, et al., "Microstructure and room temperature mechanical properties of NiAl-Cr(Mo)-(Hf, Dy) hypoeutectic alloy prepared by injection casting," Trans. Nonferrous Met. Soc. China, 23, 983-990 (2013).

11. R. I. Barabash, W. Liu, J. Z. Tischler, et al., "Phase-specific elastic/plastic interface interactions in layered NiAl-Cr(Mo) structures," Acta Mater., 60, No. 8, 3279-3286 (2012).

12. Q. H. Wu, J. Zhang, and Y. S. Luo, "Composition and mechanical property of DD6 superalloy revert," Mater. Sci. Forum, 788, 488-492 (2014).

13. L. Y. Sheng, F. Yang, J. T. Guo, and T. F. Xi, "Anomalous yield and intermediate temperature brittleness behaviors of directionally solidified nickel-based superalloy," Trans. Nonferrous Met. Soc. China, 24, 673-681 (2014).

14. C. T. Liu and J. A. Horton, Jr., "Effect of refractory alloying additions on mechanical properties of near-stoichiometric NiAl," Mater. Sci. Eng. A, 192-193, 170-178 (1995).

15. L. Y. Sheng, Y. Xie, T. F. Xi, et al., "Microstructure characteristics and compressive properties of NiAl-based multiphase alloy during heat treatments," Mater. Sci. Eng. A, 528, 8324-8331 (2011).

16. A. Bhowmik, K. M. Knowles, and H. J. Stone, "Microstructural evolution and interfacial crystallography in $\mathrm{Cr}_{-} \mathrm{Cr}_{2} \mathrm{Ta}$," Intermetallics, 31, 34-47 (2012).

17. D. R. Johnson, B. F. Oliver, R. D. Noebe, and J. D. Whittenberger, "NiAl-based polyphase in situ composites in the NiAl-Ta-X $(\mathrm{X}=\mathrm{Cr}$, Mo, or V) systems," Intermetallics, 3, No. 6, 493-503 (1995).

18. B. Zeumer and G. Sauthoff, "Deformation behaviour of intermetallic NiAl-Ta alloys with strengthening Laves phase for high-temperature applications III. Effects of alloying with Cr," Intermetallics, 6, No. 5, 451-460 (1998).

19. L. Y. Sheng, J. T. Guo, W. L. Ren, et al., "Preliminary investigation on strong magnetic field treated NiAl-Cr(Mo)-Hf near eutectic alloy," Intermetallics, 19, No. 2, 143-148 (2011).

20. W. Liu, J. C. Li, W. T. Zheng, and Q. Jiang, "NiAl(110)/Cr(110) interface: A density functional theory study," Phys. Rev. B, 73, 205421 (2006).

21. H. T. Li, J. T. Guo, and H. Q. Ye, "Composition dependence of the precipitation behavior in NiAl-Cr(Mo)-(Ti, Hf) near eutectic alloys," Mater. Sci. Eng. A, 452-453, 763-772 (2007).

22. K. S. Kumar, L. Pang, C. T. Liu, et al., "Structural stability of the laves phase $\mathrm{Cr}_{2} \mathrm{Ta}$ in a two-phase Cr-Cr 2 Ta alloy," Acta Mater., 48, 911-923 (2000). 
23. F. Laves und $\mathrm{H}$. Witte, "Die Kristallstruktur des $\mathrm{MgNi}_{2}$ und seine Beziehungen zu den Typen des $\mathrm{MgCu}_{2}$ und $\mathrm{MgZn}_{2}$," Metallwirtschaft, 14, 645-649 (1935).

24. D. R. Johnson, X. F. Chen, B. F. Oliver, et al., "Processing and mechanical properties of in-situ composites from the NiAl-Cr and the NiAl- $(\mathrm{Cr}, \mathrm{Mo})$ eutectic systems," Intermetallics, 3, No. 2, 99-113 (1995).

25. L. Y. Sheng, W. Zhang, J. T. Guo, et al., "Microstructure evolution and mechanical properties' improvement of $\mathrm{NiAl}-\mathrm{Cr}(\mathrm{Mo})-\mathrm{Hf}$ eutectic alloy during suction casting and subsequent HIP treatment," Intermetallics, 17, No. 12, 1115-1119 (2009).

26. G. Z. Liu, J. Qiu, Y. C. Jiang, et al., "Light induced suppression of Kondo effect at amorphous $\mathrm{LaAlO}_{3} / \mathrm{SrTiO}_{3}$ interface," Appl. Phys. Lett., 109, No. 3, 031110 (2016).

27. L. Y. Sheng, J. T. Guo, C. Lai, and T. F. Xi, "Effect of $\mathrm{Zr}$ addition on microstructure and mechanical properties of $\mathrm{NiAl} / \mathrm{Cr}(\mathrm{Mo})$ base eutectic alloy," Acta Metall. Sin., 51, No. 7, 828-834 (2015).

28. L. Y. Sheng, F. Yang, T. F. Xi, and J. T. Gu, "Investigation on microstructure and wear behavior of the $\mathrm{NiAl}-\mathrm{TiC}-\mathrm{Al}_{2} \mathrm{O}_{3}$ composite fabricated by self-propagation high-temperature synthesis with extrusion," J. Alloy. Compd., 554, 182-188 (2013).

29. L. Y. Sheng, C. Lai, F. Yang, et al., "Microstructure and wear behaviour of ceramic particles strengthening NiAl based composite," Mater. Res. Innov., 18, S4-544S4-549 (2014). 